\title{
How Blockchain Make Better the Supply Chain in the Automotive Industry
}

\author{
Sanae Yahiaoui, Fayçal Fedouaki, Ahmed Mouchtachi
}

\begin{abstract}
The traditional SC is a model that meets the supply expectations of intermediaries. There are gaps in this model, such as relationships between members of the supply chain or consumers' ignorance of information about the source of the products. This article presents a new SC model with Blockchain. To do this, we carried out a comparison between the traditional supply chain and the new chain with the Blockchain in order to designate a model that meets our needs. This BKC method is a new technology that offers effective and confident solutions in businesses. This new model reinforces the reliability of the system based on transparency and traceability in all chain operations, assets and financial means and removes many of the disadvantages of the traditional supply chain. In addition, the Blockchain coordinates all transactions and multi-agents in the SC
\end{abstract}

Keywords : Supply Chain, BKC technology, SC Model.

Table of abbreviations

SC : Supply Chain

BKC : Blockchain

\section{INTRODUCTION}

Currently Blockchain has become a very well-known method. It is in the form of several blocks of information linked to each other. This method was find out by several researchers in 1991 and was originally intended to date digital records so that they cannot be touched. However, its potential remained unknown until Satoshi Nakamoto adapted it in 2009[1] to establish Bitcoin1 digital cryptocurrency. $\mathrm{BKC}$ is a general ledger available and open to all. The data that is saved on the Blockchain becomes secure and very difficult to modify, this functionality makes the Blockchain useful and important. Blockchain expected to become essential technology for universal supply chains by 2025 . This is shown in a report just published by Capgeminiin 2018 [2]: " Could Blockchain Start a New Period of Transparency and Trust in the SC ? Which aims to explain how companies are preparing for the arrival of the Blockchain [3]. The Blockchain is an important unit of the technological trends that influence companies. Blockchain has appeared as a important troubled multi-purpose method for businesses that

Revised Manuscript Received on February 05, 2020.

* Correspondence Author

Sanae YAHIAOUI*, Laboratory of SEISEE, ENSAM of Casablanca Morocco. Email: yahiaouisanae@gmail.com

Fayçal FEDOUAKI, Industrial Engineering Department, ENSAM of Casablanca Morocco. Email: fedouaki.faycal@gmail.com

Ahmed MOUCHTACHI, Director of ENSAM of Casablanca Morocco. Email: Ahmedmouchtachi@yahoo.fr

(C) The Authors. Published by Blue Eyes Intelligence Engineering and Sciences Publication (BEIESP). This is an open access article under the CC BY-NC-ND license (http://creativecommons.org/licenses/by-nc-nd/4.0/) build trust as they interact with one another [4]. Blockchain has many potential benefits ranging from technical improvements to social and economic improvements [5] and its commitments are high [6]. However, Forrester's analysis estimated that $90 \%$ of commercial projects based on Distributed Ledger Technology (DLT) are discontinued for the 2015-2017 period. The adoption of BKC in the SC is precise in the country [7] and must take into account the context. Until these years, most of the literature has focused on the technological level, inscripting the technological challenge for practice the Blockchain for P2P processes [4]. Blockchain is currently attracting interest from several sectors: finance [8;9], health care [10], utilities sector, public sector and other sectors [11]. The cause for this growth: with a BKC, software or programs that only work through a trusted intermediary. Now they can be operated freely, without a verification system and the same options with the same degree of reliability. This operation was not valid before the existence of the Blockchain. With the implementation of the Blockchain, networks without trust appeared. This is possible because no other user is needed [12]. By the absence of intermediaries, the time to execute transactions become faster between processes. In addition, the option of cryptography in the Blockchain allows to have information security [13].

The automotive industry needs to take advantage of three critical parameters such as trust, traceability and transparency. Other advantages of Blockchain is that it can offer a more efficient exchange solution between all interactions within a large professional network of suppliers, manufacturers and customers. We seek to maintain these parameters still valid for the necessity of the use of Blockchain for the automotive industry.

This article presents a new supply chain model based on BKC method. The purpose of this designed model is to keep all components of the supply chain attached to the Blockchain with a guarantee of high level of traceability and security and transparency. This article consists of a first part of general context of Blockchain with a global definition. In the second part, we will present a literature review on the history of the Blockchain. For the third part, it will be described Blockchain usage statistics with current use cases of the Blockchain. Then, in the fourth section, we will explain BKC in the automotive SC. Indeed, we will carry out a case study for the automotive sector based on a detailed methodology that describes the difference between the traditional supply chain and the supply chain with Blockchain projected on the automotive sector, with a quote of the advantages offered with the new version of supply chain. While the last section, will deal with potential paper discussions and conclusions. 


\section{DEFINITION OF BLOCKCHAIN}

Fundamentally, a BKC is represented as a open book: a chain classified in order of "blocks" which contains a record of network activity and since the addition of the last block to the chain, each block is validated successively [14] and each block could be defined as an information code. Theoretically, adding data to the Blockchain is accessible by anyone by performing transactions on the network, anyone can be at any time, but no one can change without proper authorization.

Blockchain is a transparent, secure technology with no central control unit for storing and transmitting information.

In addition, a blockchain is in the form of a secure database, which keeps the history of all transactions. The blockchain shares with all the interesting parties without the need for intermediaries. This allows you to check the validity of the channel by its users.

\begin{tabular}{|c|c|c|}
$\begin{array}{c}\text { Bloc A } \\
\text { Transaction 1 } \\
\text { Transaction 2 } \\
\text { Transaction 3 }\end{array}$ & $\begin{array}{c}\text { Bloc C } \\
\text { Transaction 4 } \\
\text { Transaction 5 } \\
\text { Transaction 6 }\end{array}$
\end{tabular}$\quad \begin{gathered}\begin{array}{c}\text { Bloc D } \\
\text { Transaction 7 } \\
\text { Transaction 8 } \\
\text { Transaction 9 }\end{array} \\
\\
\text { Transaction11 } \\
\text { Transaction12 }\end{gathered}$

Fig. 1.: Sets of blocks which contains transactions linked to each other directly without intermediary

There are two types of Blockchain: The first type is a confidential Blockchain, access to which is limited to a certain number of users. The second is a standard Blockchain with free access to all, it can therefore be compared to a ledger of public accounts, anonymous and tamper-proof. The mathematician Jean-Paul Delahaye, declares that it is necessary to imagine a very large valid and open book for the world, on which it imports who can write, but which is impossible to erase or destroy " [4].

For the first time the BKC is a technology that allows a set of different entities that do not trust to exchange value securely on the internet without intermediary. By default, the "extraction" process requires validation of transactions and secures and makes information entered in the chain more reliable. BKC technology can be defined like the technology that provides the internet for transactions [15]. Indeed, the Blockchain has a powerful feature, its ability to obtain a distributed network to reach a consensus on the state of the data, and agreement on the rules of the network without central governing body. Moreover, any user can propose actions to improve a system, but these are not implemented and provided until all concerned parties accept them.

The network, therefore, increased transparency and confidence. In a typical Blockchain interaction, trust between a distributed network is possible through the validation or exploration process, where each new transaction is checked by the entire network before being added to a Blockchain.

\section{BACKGROUND LITERATURE}

These days, BKC is a very well-known technology. It is in the form of several chained blocks carrying information.

Since 2008, the development of Bitcoin became the first example of a Blockchain application. This wide spread cryptocurrency provides a real-life solution to the challenge of trust in a decentralized system. It has the force of making transactions unable to be found but also verifiable and continual. BKC is a open book that can be accessed by everyone, which eliminates the need for a centralized bank because each process, agreement, transaction and each task is digitally coded by a record and a signature which can be designated, validated, stored and disseminated [16].

A Blockchain is a disseminated database that is shared and replicated between users in a network [17]. It was deposited by Bitcoin [18] in order to treat the problem of double spending [19]. Due to the way Bitcoin or minor nodes mutually validate agreed transactions, the Bitcoin BKC determines the landowners and indicates what they have. [20].A BKC is made based on cryptography. The blocks are identified numerically by their own code, and each block is referenced by the code of the previous block. This identification create a link between the blocks constituting a BKC. [21;22]. For this, with a certain security, users can communicate with a public and private blockchain.

By implementing blockchain, smart contract are available to execute operations between different users in a fast and efficient way. [23].This concept was introduced in 1994 according to Nick Szabo (1997) and the definition of a smart contract is a computerized transaction protocol that validates the requirements of a contract " [24]. NickSzabo (1997) submitted that the contractual clauses are transferred to the code, which limits the presence of intermediaries in transactions between BKC processes, a smart contract is a script stored at a single address in a Blockchain [25;26]. By specifying the address on the Blockchain, we can trigger a contract chip in a transaction.

\section{STATISTICS OF USE OF BLOCKCHAIN}

This report indicates that the use of this technology in supply chains should be democratized by 2025 . Today, only $3 \%$ of organizations that already operate the Blockchain use it on a large scale, $10 \%$ have a pilot program and $87 \%$ are still in the experimental stages of this technology [3].

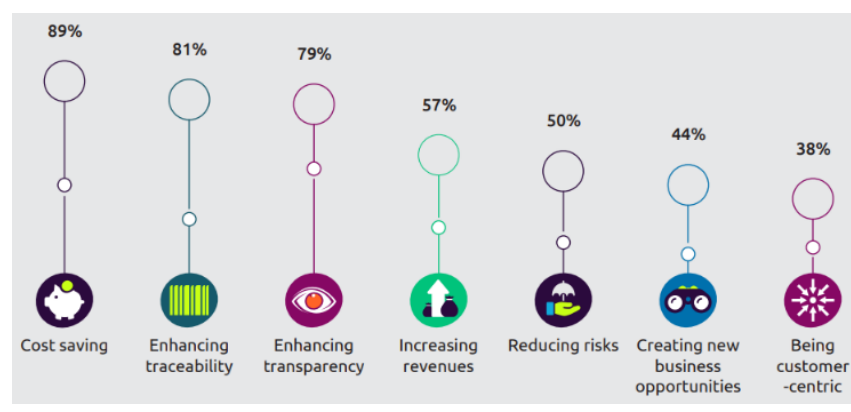

Fig. 2.: Drivers of Blockchain investments [3].

In Europe, the United Kingdom (22\%) and France (17\%) are the most advanced countries for pilot or large Blockchain deployments, while in terms of investment, the United States (18\%) come first. The "pioneers" of the use of these technologies are convinced that the Blockchain will keep its promises: more than $60 \%$ of the respondents of the study believe that the technology is already transforming their mode of collaboration with their partners [3]. 
The report shows that Blockchain investments are mainly driven by cost reduction (89\%), traceability optimization (81\%) and improved transparency (79\%).

In addition, the Blockchain manages the flow of information in a more secure, fast and transparent way. The technology is valid for the most critical functions of the supply chain, from production monitoring to monitoring the supply chain while ensuring compliance with applicable regulations.

\section{CURRENT USE CASES OF THEBLOCKCHAIN}

The Capgemini Research Institute report (2018) identified 24 cases of use of the Blockchain. From the exchange of carbon credits to the management of supplier contracts and the fight against counterfeits [2]. Furthermore, Capgemini (2018) has applied these use cases to the retail, industry and consumer products sectors and shows that the Blockchain can be used to monitor production, the source of contracts and their inventory and the traceability of products and services [2].

In the consumer goods sector, companies are putting Blockchain into practice primarily for tracking and identifying products: experiments have been set up at Nestle, Unilever and Tyson Foods. As for retail players, like Starbucks, their Blockchain tests focus on digital marketplaces and the fight against counterfeits. The Blockchain can also ensure the integrity of food products by making it possible to monitor food from the production site to the plate, thus avoiding the risk of contaminations and Recalls of consecutive products [2].

\section{BLOCKCHAIN FOR AUTOMOTIVE SUPPLY CHAINS}

Blockchain technology uses a decentralized network so it is considered an immovable financial transaction system. System members confirm that even with the absence of a central management authority it still guarantees that data security because bad users if they want to modify information should hack multiple data storage locations.

There are several real uses of Blockchain in the automotive industry. For example, the toll system as well as electric vehicle charging stations as well as a public traceability system for tracking vehicles and parts in the supply chain. The evolution of technology, however, in the dark world of cryptocurrency bitcoin, has left some industries hesitant to adopt it.

Sachin Lulla, automotive manager for IBM, has announced that Blockchain is a dirty buzzword, but very few people understand it, which is why these groupings of companies play an important role, they give life to technology.

Then, Teodoro Lio, automotive and industrial director at Accenture, a consulting company, which is part of the consortium, says Blockchain can be dead before it starts if a single component grows, it will be so difficult for the industry, then It will not be just two automakers to make it happen.

The initial objective of the consortium will be to bring automakers identify vehicles leaving the chain by digital identity codes, which will allow them to access Blockchain platforms that offer mobility services. This effect can create new sources of earnings for automakers who want to convert vehicle locations and user data to currency. This could unlock new sources of revenue for automakers who want to monetize vehicle locations and consumer data.

Yet, the impact of Blockchain goes more than financial operations. Using its intermediary step, pseudonym protection and security option, several companies have started to study its usefulness in CS, in several sectors of the origin and traceability of products, in international maritime transport and trade supply chain, secure data and record exchange, smart contracts, anti-corruption and humanitarian assistance [27].

In addition, the process with more transparency and trust [28] will be involved in more collaboration between users of the SC [29], trust [30], responsibility also as security [31] indeed. Even if these crucial advantages, the literature regarding empirical studies [32] on the Blockchain in the context of the SC is rare. Yet, researchers have recently started researching to understand the effectiveness of blockchain adoption in SC contexts [33;34;35].

\section{METHODOLOGY}

A new model of automotive sector is presented in this article. The proposed model includes a chain of blocks, an integrated management system to coordinate the follow-up of automotive sector products in the automotive supply chain based on adding Blockchain.

In the figures 3 and 4 below, we describe two types of supply chain, a current traditional chain, and another new supply chain with Blockchain.

\section{A. Traditional Supply Chain}

The traditional model starts with the buyer and the importer. These two members of the SC are sending their products and information to the next zone of the SC. In this next zone are export and sales, production and storage are the intermediate layers that are responsible for the manufacture and realization of the commodities received through the supply chain. Finally, the Customer.

The major inconvenience of this type of model is that the information is centralized in each of the areas of the SC, This says that other areas and components of SC cannot see the operations carried out. The consequence of this drawback is that the end consumer cannot verify the source of the product to be purchased. Also, the reliability of consumer data is not guaranteed.

\section{B. Supply Chain with Blockchain}

With the creation of Blockchain now, the latter ensures that all users and corposants of the SC record all their operations in the BKC. This allows increased security in operations. Also, this technology addresses the inconvenience of the traditional SC. The information is decentralized and each member can read important information for his transaction in the Blockchain. The consumer can see the information on the components of its products and the details of the manufacturing supplier. 
With this Blockchain model in the supply chain for manufacturing systems is illustrated in Figure 5.

The proposed approach includes a decentralized distributed system that uses the agent method and smart contracts to collect, store and manage key information for each product throughout its life cycle. This creates a shared and secure exchange record for each product.

Each process sends its parameters and data to the Blockchain. Moreover, the processes communicate with each other by means of transactions that allow information to be exchanged in the chain.

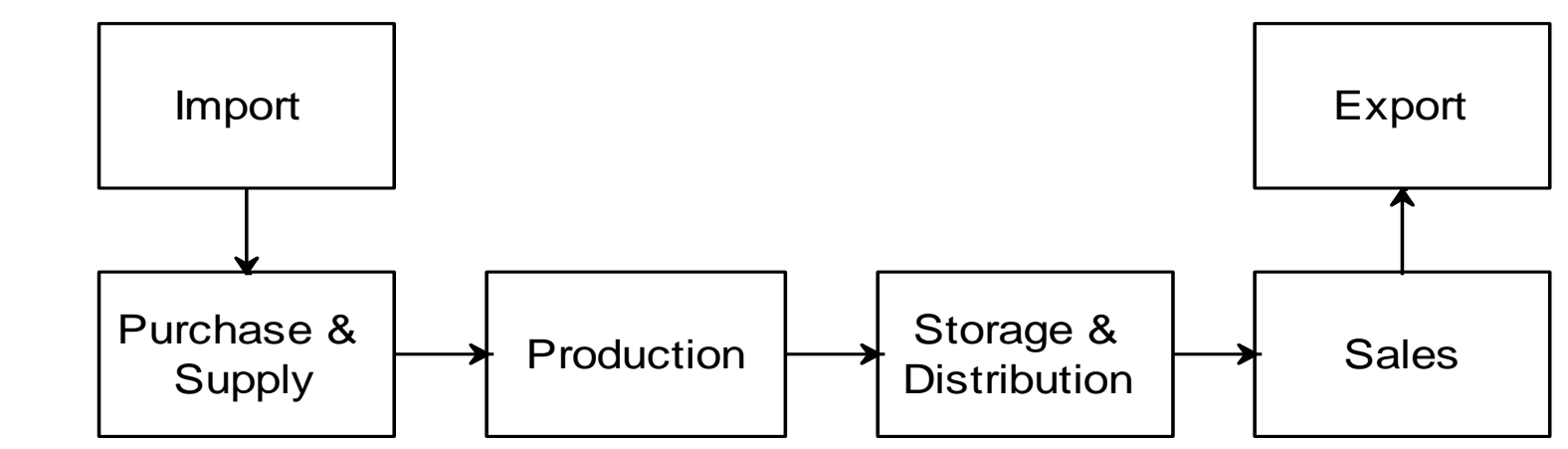

Fig. 3.: Traditional Supply Chain

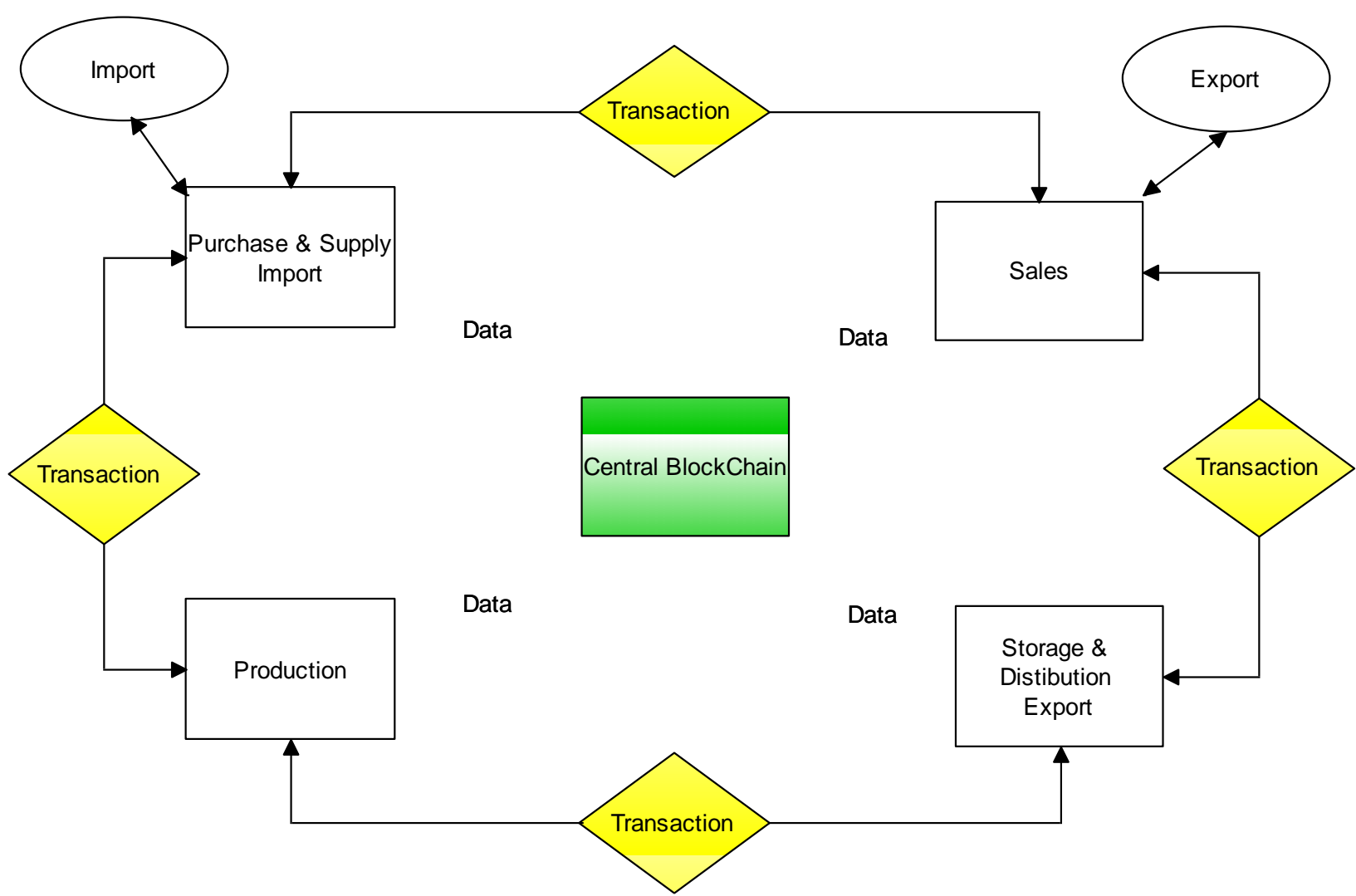

Fig. 4.: Supply chain witch Blockchain

\section{CASE STUDY IN AUTOMOTIVE SUPPLY CHAIN}

The proposed model facilitates the collection of a large amount of data on products and users in the automotive industry, which can be an advantage for different people in this supply chain who have a direct or indirect relationship with it. This will allow consumers to easily access data specific to any product manufactured using a supply chain via Blockchain. Allowing them to ensure that the companies involved in the design, manufacturing can better understand how their products are made. This level of feedback can improve their technology, marketing and sales. The new model of the supply chain is created (see Figure.5). The model has five processes: 1) Import and purchase. This

process sends transactions through agents and coordinates all operations to be performed (import, purchase of equipment, etc.) with an intelligent contract. 2) In production is the process that coordinates and guarantees the traceability of manufactured parts, etc. 3) In the process of storing and selling the agent sends transactions of all the tasks performed at this stage. 4) The sale and export ensures the delivery of the product to the customer. The agent in this process coordinates the sale of products and ensures customer satisfaction. 5) Blockchain Center. This process is synchronized with all other processes in the chain through agents so that all data from all transactions is properly stored in the Blockchain.

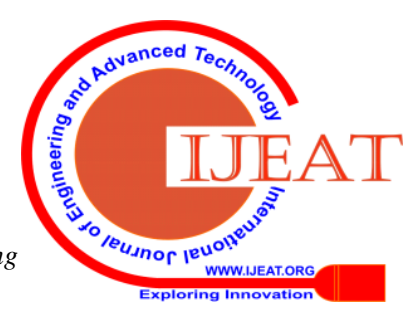




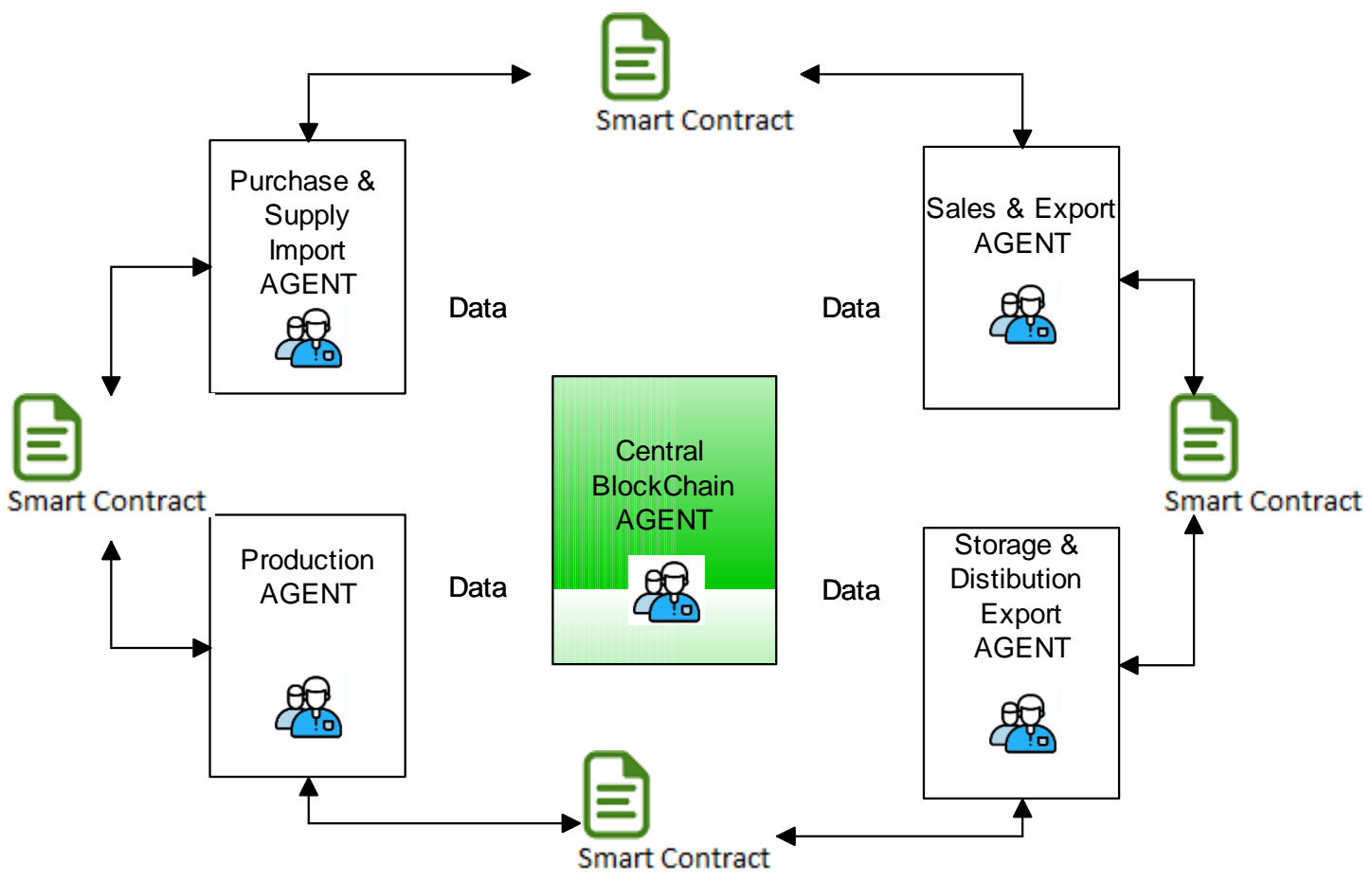

Fig. 5.: The Automotive Supply Chain with Blockchain

\section{RESULT ANALYSIS AND DISCUSSION}

In this table we show the best advantages of traditional supply chain and Blockchain.

Table- I: Advantages Of Supply Chain \& Blockchain

\begin{tabular}{|l|c|c|}
\hline \multicolumn{1}{|c|}{ Advantages } & $\begin{array}{c}\text { Traditional } \\
\text { Supply Chain }\end{array}$ & Blockchain \\
\hline 1-Transparency & $\times$ & $\times$ \\
2-Freedom of reading and writing & $\times$ & $\times$ \\
3-Decentralization & & \\
4-Data distribution across the network & & \\
5-Security & $\times$ & $\times$ \\
6-Centralization & & $\times$ \\
7-Iintelligent and automatic contract & $\times$ & $\times$ \\
8-Traditional contract & & $\times$ \\
9-Fluid exchange & & \\
10-Traceability & & \\
\hline
\end{tabular}

This article presents a new supply chain based on the Blockchain to improve the traditional SC. The new things of this chain is that it stores it is like a server that includes all transactions and operation in the proposed SC. In addition, the agent system employs intelligent contracts for an efficient management of all supply chain processes, since intelligent contracts are computer protocols that facilitate, verify and execute the negotiation or execution of a contract. Therefore, it is not necessary to pay intermediaries and this saves time and avoids conflicts.

This Blockchain is undeniably faster, cheaper and safer than traditional systems.

Our model can be valid to improve all types of chains. The case study conducted in this article is targeted for the automotive sector. Our model has improved the security and efficiency of the information because it is run by the agent system. In fact, the BKC offers the automotive system a set of security and service features. Product tracking can be done, origins and sources of manufacturing and all that is proven using all the transactions that can be stored and unmodified.

The most in our model is the agent system that verifies all contract terms whether they are applicable or not. In addition, this system is able to track and authenticate commands. A payment system is introduced in the SC via the BKC in order to carry out purchase and sale operations.

Indeed, the Blockchain technology will become a fundamental element for the performance of large companies. In implementing Blockchain, all interested parties in the supply chain become more agile and more productive. Therefore, the Blockchain offers to the field of industries a package of benefits and advantages to get started, trust, transparency and verifiable property among the components offering. The value and originality will once again be redefined. The Blockchain will be the next step in modern manufacturing and will see a paradigm shift towards intelligent supply chains that merge cyber and physical systems.

\section{CONCLUSION}

In this article, a new model of the SC based on BKC and smart type contracts is presented. The existence of Blockchain to improve the traditional supply chain aims to overcome some data barriers and traceability of the current chain. Such as lack of security, information sharing, and system integration issues. This paper presents a Blockchain that stores all operations in the SC of the proposed case study. In addition, the agent system uses transactions to more effectively manage all parts of the SC.

Our model is used to improve the supply chain in the automotive sector. The proposed model will enhances various trust, safety and efficiency through automation made by the agent system.

Published By:

Blue Eyes Intelligence Engineering 
By integrating the Blockchain, we provide the car system with strong safety features. Import and export goods can be tracked; manufacturing authenticated and proof of all transactions can be stored and not manipulated.

This work was mainly focused on a Blockchain-based intelligent contract model, which reduces the workload of the automotive production chain since smart contract in the Blockchain allows the execution of contracts when the required conditions are met.

As far as future work is concerned, even if the Blockchain evolves seriously, it is still not suitable for Small and medium-sized Enterprises (SMEs). It would be relevant to analyze the challenges and opportunities of its integration into existing IT systems in SMEs. Infrastructures and to what extent the main drivers have succeeded. Other studies are the implementation of the supply chain via BKC in SMEs by examining the effect of intelligent contract on current models in the automotive sector.

\section{REFERENCES}

1. Nakamoto S. Bitcoin: A peer-to-peer electronic cash system. Manubot; 20 November 2019.

2. Capgemini, "The blockchain, new engine of the supply chain", 2018. Available:http://www.informatiquenews.fr/la-blockchain-nouveau-mot eur-de-la-supply-chain-58627

3. Blockchain France "what is the blockchain?". Available: https://blockchainfrance.net/decouvrir-la-blockchain/c-est-quoi-la-bloc kchain/36/

4. J Yli-Huumo, D Ko, S Choi, S Park, K Smolander - PloS one, "Where is current research o, Blockchain technologie? - A systematic review “journals.plos.org. Published October 3, 2016. Available : https://doi.org/10.1371/journal.pone.0163477

5. S Schuetz, V Venkatesh, "Blockchain, adoption, and financial inclusion in India: research opportunities" International Journal of Information Management, 2019 - Elsevier.

6. S Ølnes, J Ubacht, M Janssen. "Blockchain in government: Benefits and implications of distributed ledger technology for information sharing" Journal Government Information Quarterly Volume 34, Issue 3, September 2017, Pages 355-364.

7. MM Queiroz, SF Wamba, "Blockchain adoption challenges in supply chain: An empirical investigation of the main drivers in India and the USA", International Journal of Information Management, Elsevier Volume 46, June 2019, Pages 70-82.

8. (Aug.1, 2002). Announcing the Secure Hash Standard. Available: http://csrc.nist.gov/publications/fips/fips180-2/fips180-2.pdf

9. AntonopoulosA.M, Mastering Bitcoin: Unlocking Digital Cryptocurrencies, 1sted.Sebastopol, CA, USA: O'Reilly Media, Inc., 2014.

10. Bogdan Okresa Durik. "Organisational Metamodel for Large-Scale Multi-Agent Systems: First Steps Towards Modelling Organisation Dynamics". ADCAIJ: Advances in Distributed Computing and Artificial Intelligence Journal, Salamanca, v. 6, n. 3, 2017.

11. Casado-Vara R, Corchado J. M. Blockchain for Democratic Voting: How Blockchain Could Cast off Voter Fraud. Orient.J. Comp. Sci. and Technol; 11(1).

12. Chamoso, P., Rivas, A., Mart'in-Limorti, J.J., andRodr'iguez,S. AHash Based Image Matching Algorithm for Social Networks. In Advances in Intelligent Systems and Computing (Vol.619, pp.183-190, 2018.

13. Li, T., Sun, S., Boli'c, M., and Corchado, J. M. Algorithm design for parallel implementation of the SMC-PHD filter. Signal Processing, 119, 115-127, 2016.

14. S. Bogart and K. Rice, "The Blockchain Report:Welcome to the Internet of Value," 2015.

15. Aleksandar Subic, Yang Xiang, Sudhir Pai et Erwann de La ServeCapegimini ' Blockchain and Industry 4.0 Why Blockchain is at the heart of the Fourth Industrial Revolution andDigitalEconomy? 2018.

16. M. Mainelli and A. Milne, "The Impact and Potential of Blockchain on the Securities Transaction Lifecycle," 2016.

17. J"org Bremer, Sebastian Lehnhoff. "Decentralized Coalition Formation with Agent-based Combinatorial Heuristics". ADCAIJ: Advances in Distributed Computing and Artificial Intelligence Journal, Salamanca, v. 6, n. 3, 2017.

18. Nakamoto S., "Bitcoin: A Peer-to-Peer Electronic Cash System", 2008. Available: https://bitcoin.org/bitcoin.pdf

19. Double-Spending - Bitcoin WiKi, accessed on Mar. 15, 2016.

20. Eris Industries Documentation-Blockchains, accessed on Mar. 15, 2016.Available:https://docs.erisindustries.com/ explainers/blockchains/

21. AntonopoulosA.M.,MasteringBitcoin:UnlockingDigitalCryptocurrenci es,1sted.Sebastopol,CA,USA:O’ReillyMedia,Inc.,2014.

22. CARDOSO, Rafael Cauê; BORDINI, Rafael Heitor. "A Multi-Agent Extension of a Hierarchical Task Network Planning Formalism". ADCAIJ: Advances in Distributed Computing and Artificial Intelligence Journal, Salamanca, v. 6, n. 2, p. 5-17, jun. 2017. ISSN 2255-2863.Available:

$<$ http://revistas.usal.es/index.php/2255-2863/article/view/ADCAIJ201 762517>.

23. Gonz'alez A., Ramos J., De Paz J.F., Corchado J.M. "Obtaining Relevant Genes by Analysis of Expression Arrays with a Multi-Agent System". ADCAIJ: Advances in Distributed Computing and Artificial Intelligence Journal, Salamanca, v. 3, n.3, 2014.

24. Szabo N., Smart Contracts 1994. Available http://szabo.best.vwh.net/smart.contracts.html

25. Szabo N., "The Idea of Smart Contracts", 1997. Available http://szabo.best.vwh.net/smart_contracts_idea.html

26. SHIRAZ AHMED, "Automakers, suppliers team up to develop blockchain technology', May 02, 2018.

27. Wang, Y., Han, J. H., Beynon-Davies, P., "Understanding blockchain technology for future supply chains: a systematic literature review and research agenda". Supply Chain Management: An International Journal, 24(1), pp.62-84, (2019a).

28. Lu, Q. and Xu, X. “Adaptable Blockchain-Based Systems: A Case Study for Product Traceability", IEEE Software, 34(6), pp. 21-27, 2017.

29. Aste, T., Tasca, P. and Di Matteo, T. "Blockchain Technologies: The Foreseeable Impact on Society and Industry", Computer, 50(9), pp. 18-28, 2017.

30. Kshetri, N., “1 Blockchain's roles in meeting key supply chain management objectives", International Journal of Information Management. Elsevier, 39(June2017), pp. 80-89, 2018.

31. Biswas, K., Muthukkumarasamy, V. and Tan, W. L.”Blockchain Based Wine Supply Chain Traceability System", Future Technologies Conference, December 2017.

32. Fosso Wamba, S. et al. "Bitcoin, Blockchain, and FinTech: A Systematic Review and Case Studies in the Supply Chain", Production Planning and Control, June 2018.

33. Francisco, K. and Swanson, D. "The Supply Chain Has No Clothes: Technology Adoption of Blockchain forSupply Chain Transparency", Logistics, 2(1), p. 2, 2018.

34. Kamble, S., Gunasekaran, A. and Arha, H. 'Understanding the Blockchain technology adoption in supply chains-Indian context', International Journal of Production Research. Taylor \& Francis, 0(0), pp. 1-25, 2018.

35. Queiroz, M. M. and Fosso Wamba, S., "Blockchain adoption challenges in supply chain: An empirical investigation of the main drivers in India and the USA", International Journal of Information Management, 46, pp.70-82, 2019.

\section{AUTHORS PROFILE}

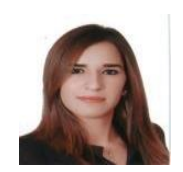

Sanae Yahiaoui, Ph.D. in Logistics Engineering, at Laboratory of Structural Engineering, Intelligent Systems and Electrical Energy at National School of Arts and Crafts Casablanca, Morocco

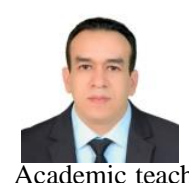

Faycal Fedouaki is currently serving as Associate Professor and researcher at Hassan 2 University of Casablanca. He received his $\mathrm{PhD}$, Master of research and Master of Science degree from sciences and technologies Faculty, at Hassan 1st University of Settat. He has total Academic teaching experience of more than 8 Years.His area of interest includes systems optimization,Logistics and lean manufacturing

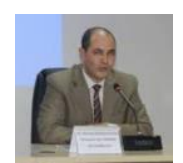

Ahmed Mouchtachi, Professor and researcher. Author of several research papers and supervisor of several thesis. He is the head of the Higher National School of Arts and Crafts of Casablanca, Hassan 2 University. He is the head of the research Laboratory of Structural Engineering, Intelligent Systems and Electrical Energy.

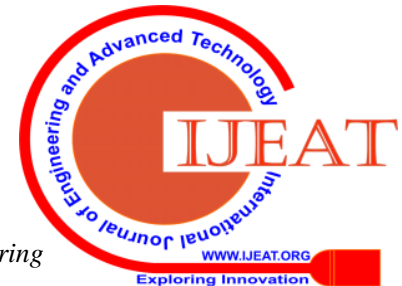

